\title{
Analysis of Container Problems in Exception Area at PT. Terminal Petikemas Surabaya uses the Lean Six Sigma Method
}

\author{
Vivi Mentari Dewi ${ }^{1 *}$, Iis Dewi Ratih ${ }^{1}$
}

\begin{abstract}
PT Terminal Petikemas Surabaya is a company engaged in logistics, container services. Since the end of December 2019, PT Terminal Petikemas Surabaya began implementing a gate automation system at gate in exports. One thing that is done to support the gate automation is the Exception Area which is used as a data repair place for trucks that experience problems during the gate-in export process before heading to the stacking field. Containers that are constrained during the gate-in process indicate that there are procedural errors carried out by internal companies and external parties, such as drivers, forwarders, and importers related to administrative and technical problems. This research focuses on controlling the quality of container problems that enter the exception area by using a statistical method in the form of lean six sigma. The purpose of this study is to determine the average length of time to resolve containers for each problem, to $\mathrm{know}$ the quality of and the sigma level of the average length of time to resolve containers that enter the Exception Area based on the average number of container problems entering the Exception Area according to five problem criteria, knowing the problems that cause the most of the containers that enter the Exception Area. The results of the analysis in this study are the average length of time for containers that enter the Exception Area for each problem as a whole, the highest is caused by the system and the lowest is due to the closing time. The average number of container problems that enter the Exception Area in accordance with the five criteria, the problem has been controlled statistically with the most problem causes caused by the system, and the sigma level value is obtained from the average number of container problems that enter the Exception Area according to the five problem criteria which is 3,395 , which means the variation or diversity of container problems that enter the exception area based on the problems of the containers that enter the Exception Area according to the five criteria, the problem is quite large.
\end{abstract}

Keywords - Closing time, Exception area, Gate in automation, Lean, Six sigma

\section{INTRODUCTION}

$\mathrm{T}$ erminal Petikemas Surabaya, is a company engaged in providing container terminal facilities for domestic and international trade efficiently and on time. In connection with the Regulation of the Minister of Transportation Number 120 of 2017 concerning Services for Receiving Orders Electronically (Delivery Order Online) of Goods at the Port, to answer this regulation PT Terminal Petikemas Surabaya uses Clique 247 to make online bookings in making job orders without having to come to the place and process transactions more efficiently. Based on the Ease of Doing Business released by the World Bank in 2020, it shows that Indonesia is ranked 73 rd out of 190 . Efforts made by the government to increase the ranking are by recommending gate automation, namely the process of entering containers carried by head trucks with independent transactions made by the driver. Gate automation at PT Terminal Petikemas Surabaya was realized at the export gate that has been running for approximately 3 months, starting from the end of December 2019. One of the things done to support this gate automation is the Exception Area which is used as a place to improve data for trucks that experience problems during the gate-in process before heading to the container yard. This study focuses on the problems of containers that enter the Exception Area which aims to determine the duration of handling for problems in each container, determine the quality of the resolution process for container problems that enter the Exception Area based on five problem criteria, determine the highest problems are the highest causes of containers that enter the Exception Area that cause containers to enter the Exception Area based on the five problem criteria (booking, block, closing time, damage, and system). The purpose of this study is to determine the quality control of the average number of container problems that enter in Exception Area at PT Terminal Petikemas Surabaya with control charts, pareto chart, ishikawa, also using six sigma method. Companies can find out which problems are the highest cause and longest resolution of containers that enter the Exception Area, so that they can make improvements to improve the performance of export activities. The limitation of the problem in this study is the containers that enter the Exception Area of PT Terminal Petikemas Surabaya on shift 3 (16:00 - 23:00 WIB) at the export gate. This research was conducted until the improve step, while the control step was used for company recommendations in improving the performance of export activities.

\section{Poisson Distribution Test}

The Poisson distribution test is used to determine the distribution of an observational data whether it follows a Poisson distribution or not. This test is included in the Chisquare test. The Poisson distribution test assumptions are as follows.

1. Data is taken from a random sample of observations with different numbers.

2. Measurement using a nominal scale.

\footnotetext{
${ }^{1}$ Department of Bussiness Statistics, Institut Teknologi Sepuluh Nopember, Kampus ITS Sukolilo, Surabaya, 60111, Indonesia. E-mail:vivimentari9@gmail.com, iisdewiratih@gmail.com
} 
The results of the observations can be classified into a number of non-overlapping categories by utilizing all possible classifications (mutually exclusive and mutually exhautive). The number of observations in a category is called frequency [1]. The steps for the Poisson distribution conformance test are as follows.

Hypothesis:

$\mathrm{H}_{0}$ : Sample data follows a Poisson distribution

$\mathrm{H}_{1}$ : Sample data does not follow a Poisson distribution

Rejection area: Reject $\mathrm{H}_{0}$ if $\chi^{2}>\chi_{\alpha(r-k-1)}^{2}$ or

Statistics Test

$$
\mathrm{P} \text {-value }<\alpha(\text { significant level) }
$$

$$
\begin{array}{r}
\chi^{2}=\sum_{i=1}^{r} \frac{\left(O_{i}-E_{i}\right)^{2}}{E_{i}} \\
E_{i}=n F\left(x_{i}\right) \\
F\left(x_{i}\right)=\frac{e^{-\lambda} \lambda^{x}}{x_{i} !}
\end{array}
$$

Notation:

$$
\begin{array}{ll}
r & =\text { Category } \\
k & =\text { Parameters } \\
\chi^{2} & =\text { Chi-square } \\
O_{i} & =\text { Observation }-i \\
E_{i} & =\text { Expectation }-i \\
n & =\text { Sample } \\
F\left(x_{i}\right) & =\text { Probability- } i \\
e & =\text { Exponential }(2,718) \\
\lambda & =\text { Average of observation } \\
x_{i} & =\text { Observation }-i .
\end{array}
$$

\section{Control Chart $U$}

Control chart $\mathrm{U}$ is an attribute control chart where the quality characteristics of the attributes (properties), namely a quality characteristic that can only distinguish, namely between "defective" and "not defective" products.

Control chart $U$ used if in one inspection unit there are several types of defects about some products or process and havedifferent numbers of samples. The number of discrepancies in the mean per inspection unit on the control chart $\mathrm{U}$ is as follows [1].

$$
U=\frac{c_{i}}{n_{i}}
$$

Notation:

$$
\begin{array}{ll}
u & =\text { Number of defects per unit } \\
c_{i} & =\text { Number of each defect per unit } \\
n_{i} & =\text { Number of sample }
\end{array}
$$

If control chartU is a Poisson random variable, then the control limit are shown below.

$$
\begin{aligned}
& U C L=\bar{u}+k \sqrt{\frac{\bar{u}}{n}} \\
& \mathrm{LCL}=\bar{u}-k \sqrt{\frac{\bar{u}}{n}}
\end{aligned}
$$

Notation:

$$
\begin{array}{ll}
\bar{u} & =\text { Average of defects per unit } \\
k & =\text { Constanta } \\
\mathrm{n} & =\text { Number of sample }
\end{array}
$$

\section{Run Test}

The randomness test or run test is a test that functions to find out whether data has been taken randomly. One important example of this is when we are going to perform a statistical analysis of a number of available sample data. If the randomness of a sample is in doubt, we would want to have a way of getting to the analysis stage. There are many other situations in which we may wish to investigate the assumptions that have been made about the randomness of the samples in question [1].

Hypothesis:

$\mathrm{H}_{0}$ : The sample taken from a population is random $\mathrm{H}_{1}$ : Samples taken from a population are not random Test statistic: $r$ is the total number of series.

Rejection area: Reject $\mathrm{H}_{0}$ if $r<r_{\text {bottom }}\left(n_{1}, n_{2}\right)$ or $r>r_{\text {top }\left(n_{1}, n_{2}\right)}$ or $\mathrm{P}_{\text {value }}<\alpha$ (significant level)

If $\mathrm{n}_{1}$ or $n_{2}>20$, then use (6) as follows.

$$
z=\frac{r-\left[\left\{\left(2 n_{1} n_{2}\right) /\left(n_{1}+n_{2}\right\}+1\right]\right.}{\sqrt{\frac{2 n_{1} n_{2}\left(2 n_{1} n_{2}-n_{1}-n_{2}\right)}{\left(n_{1}+n_{2}\right)^{2}\left(n_{1}+n_{2}-1\right)}}}
$$

Notation:

$r \quad=$ Number of run

$n \quad=$ Number of total sample

$n_{1} \quad=$ Number of observations of the first group

$n_{2} \quad=$ Number of observations of the second group

Lean

Lean Six Sigma is a methodology that can be used to increase shareholder value by increasing improvements that focus on customer satisfaction, cost, quality, process speed and investment capital [2].

- Waste

One of the goals of the lean approach is waste elimination. Waste is an activity, delay, or material that consumes resources but does not contribute to adding value to the product. The seven waste classifications are as follows [3]:

1. Transportation, waste that occurs as a result of moving goods, which includes moving raw materials, transferring work in process (WIP), and moving the finished good. This type of waste can be reduced by reducing the distance between the departments that interact with the most.

2. Waiting, waste caused by waiting activities, such as waiting for information, raw materials, and machines. One way to reduce this type of waste is to anticipate machine downtime.

3. Overproduction, waste caused by overproduction. This type of waste can be eliminated by reducing unnecessary local inventory.

4. Defect, a type of waste caused by a product that is not in accordance with predetermined quality characteristics, in other words, the product has defects.

5. Inventory, waste caused by accumulation of goods in the form of finished good, raw material, or WIP. Examples of techniques that can be used to eliminate inventory are SMED and minimum lot sizes

6. Movement, waste caused by human movement. This type of waste can be eliminated by reducing excessive worker movement and reassigning.

7. Excess processing, waste in the form of excessive processing that is not desired by customers. Elimination of this type of waste can be done by 
reducing activities that are included in non-value added activities.

\section{Six Sigma}

Six Sigma is used to measure defective products in a process, where at the six sigma level it shows that the higher the sigma value, the smaller the tolerance level given to a product or service, so the higher the process capability [4].

Six Sigma focuses on eliminating process variations and defective products. The following are the benefits obtained from Six Sigma [4]:

1. Cost, an inefficient process that will require longer time and waste of resources. This of course will create costs that should not be incurred. Costs that arise as a result of inefficient processes are referred to as Cost Of Poor Quality (COPQ). The application of Six Sigma is able to reduce process variations so that defective products can be reduced and COPQ will decrease.

2. Customer Satisfaction, Six Sigma focuses on Critical To Quality (CTQ) which is the desire of the customer for the product. Six Sigma is able to see the critical factors of a process to reduce process variations so that product quality becomes what the customer wants.

3. Quality, the focus of Six Sigma is to reduce process variations so that defective products will be reduced. This shows that the good quality of the process or product will be better. Good quality will add value to the company in the eyes of customers and investors.

4. Impact on Employees, the application of six sigma will have a positive impact on employees. Employees will be more motivated to do a better job to get the targets that have been set. In addition, Six Sigma also instills culture and attitudes to employees so that all processes, products and services are in accordance with what customers want.

5. Growth, Six Sigma is able to reduce process variations, so that fewer defective products are produced and the products are in accordance with customer desires. This will affect the company's revenue which will increase.

6. Competitive Advantages, a company that is able to reduce costs, fulfill customer desires effectively and efficiently, has good quality will have a competitive advantage. The level of sigma achievement can be seen in Table 1 below.

TABLE 1

\begin{tabular}{ccc}
\multicolumn{3}{c}{ TIGMA LEVEL } \\
\hline \hline Level Sigma & DPMO & Yield \\
\hline 6-sigma & 3.4 & $99.9997 \%$ \\
5-sigma & 233 & $99.977 \%$ \\
4-sigma & 6.210 & $99.379 \%$ \\
3-sigma & 66.807 & $93.32 \%$ \\
2-sigma & 308.537 & $69.2 \%$ \\
1-sigma & 690.000 & $31 \%$ \\
\hline \hline
\end{tabular}

Six Sigma is done in five stages, known as DMA IC. The following is an explanation of the five stages of DMAIC according to [4].

a. Define

Define, at this stage what is done is defining the problem in detail and selecting the project. Activities carried out at this stage include:

- Business validation

- Documentation and analysis of several projects

- Determine customer needs

- Profit assessment

- Selecting a project b. Measurement

Measure, at this stage what is done is to measure the current process performance process. Activities carried out at this stage include:

- Data collection

- Analysis of variation

- Calculating the sigma level

c. Analyze

Analyze, at this stage what is done is an analysis of the factors causing the problem and the influence of these factors. Activities carried out at this stage include:

- Input-process-output analysis

- Activity analysis

- Analyze the cause of the problem

d. Improve

Improve, the activities carried out at this stage include:

- Collection of improvement ideas

- Measurement and selection of improvements

- Implementation of improvements

e. Control

Control, the activities carried out at this stage include:

- Oversee the implementation of improvements

- Evaluating the implementation of improvements

- Establish a Standard Operating Procedure (SOP).

\section{Pareto Chart}

Pareto chart is a series of bar charts depicting the frequency or effect of a process / state / problem. The diagram is arranged from highest to lowest from left to right. The left bar chart is relatively more important than the right. The name Pareto chart is taken from the Pareto principle, which says that $80 \%$ of disturbance comes from $20 \%$ of problems. Pareto chart is the frequency distribution of attribute data arranged by category from the variables that used in the research [5].

\section{Ishikawa}

The fishbone diagram or also known as the Ishikawa diagram or some call it the cause and effect diagram was introduced by someone named Kaoru Ishikawa. The idea is to think about the possible causes and reasons for the effect or problem [5].

The basic concept of a fishbone diagram is to describe a problem and its causes which are divided into main causes and other causes. These causes usually lead to 5 problems, namely:

1. Methods

2.Machines

3. Material

4. Human Resources

5. Environment

\section{METHOD}

A. Data

The data used in this study are primary data obtained through direct surveys conducted on:

Date : Week 9 and 10 (23 February 2020 - 07 March 2020)

Time : Shift 3 (16:00 - 23:00 WIB)

Place : Exception Area PT Terminal Petikemas Surabaya. 


\section{Variables}

The variables used in this study are as follows.

\begin{tabular}{cccc}
\multicolumn{4}{c}{ TABLE 2. } \\
VARIABLES & Unit \\
\hline \hline Variable & Explanation & Scale & \\
& $\begin{array}{c}\text { The number of } \\
\text { containers that } \\
\text { enter the }\end{array}$ & Rasio & Container \\
& $\begin{array}{c}\text { Exception Area } \\
\text { for each problem }\end{array}$ & & \\
&
\end{tabular}

Data Structure

The data structure used in this study is as follows.

TABLE 3.

DATA STRUCTURE OF CONTROL CHART U

\begin{tabular}{ccccccc}
\hline \hline $\begin{array}{c}\text { Subgroup } \\
\text { (Problems) }\end{array}$ & $\mathbf{1}$ & $\mathbf{2}$ & $\mathbf{3}$ & $\ldots$ & $\mathbf{n}$ & $\bar{U}$ \\
\hline 1 & $\mathrm{x}_{11}$ & $\mathrm{x}_{12}$ & $\mathrm{x}_{13}$ & $\ldots$ & $\mathrm{x}_{1 \mathrm{n}}$ & $\bar{U}_{1}$ \\
2 & $\mathrm{x}_{21}$ & $\mathrm{x}_{22}$ & $\mathrm{x}_{23}$ & $\ldots$ & $\mathrm{x}_{2 \mathrm{n}}$ & $\bar{U}_{2}$ \\
3 & $\mathrm{x}_{31}$ & $\mathrm{x}_{32}$ & $\mathrm{x}_{33}$ & $\ldots$ & $\mathrm{x}_{3 \mathrm{n}}$ & $\bar{U}_{3}$ \\
$\vdots$ & $\vdots$ & $\vdots$ & $\vdots$ & $\vdots$ & $\vdots$ & $\vdots$ \\
$\mathrm{m}$ & $\mathrm{x}_{\mathrm{m} 1}$ & $\mathrm{x}_{\mathrm{m} 2}$ & $\mathrm{x}_{\mathrm{m} 3}$ & $\ldots$ & $\mathrm{x}_{\mathrm{mn}}$ & $\bar{U}_{m}$ \\
\hline \hline
\end{tabular}

Data Structure

The analysis steps carried out in this study are described as follows.

1. Identify the problem

2. Collecting data through direct surveys in the Exception Area

3. Analyze survey data

4. Draw conclusions

\section{RESULTS AND DISCUSSION}

A. Eksploration of Data Containers that enter the Exception Area

- The average length of time and the number of containers that enter the Exception Area for each problem as a whole are presented in Figure 1 as follows.

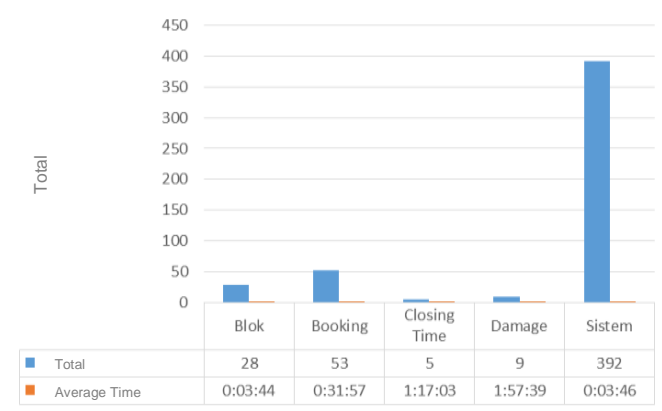

Figure 1. The average length of time for containers that enter the exception area for each problem as a whole

Figure 1 shows that the largest number of containers that entered the Exception Area from 23 February 2020 to 07 March 2020, namely on system problems as many as 392 containers with an average length of time for completion of 3 minutes 46 seconds while the smallest number was the problem of closing time as many as 5 container with an average turnaround time of 1 hour 17 minutes 3 seconds.

- The number of containers that enter the Exception Area for each problem on Day 1 to Day 14 is presented in Figure 2 as follows.

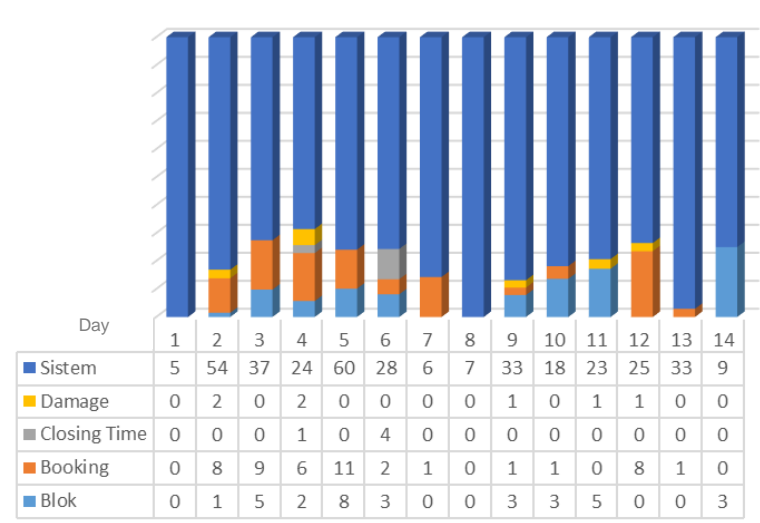

Figure 2. The Average Length of Time for Containers Entering the Exception Area for Each Problem

Figure 2 shows that the largest number of containers entering the Exception Area from February 23, 2020 to March 7, 2020, namely on block problems at most 8 containers on the 5th day, most booking problems are 11 containers on the 5th day, most of the closing time problems lots of 4 containers on the 6th day, the most damage problems are 2 containers on the 4th day, the system problems are at most 60 containers on the 5th day.

Inspection of Container Handling Process Entering the

Exception Area

The examination of the handling process for containers that enter the Exception Area is described in several subchapters as follows.

\section{- $\quad$ Examination Using Six Sigma}

The examination of the handling process for containers that enter the Exception Area using sig sigma with the DMAIC method is described as follows

1) Define

The define stage is the stage of problem formulation. Problems are determined based on Critical to Quality (CTQ). CTQ is an element of a process that is directly related to customer needs and satisfaction. The define stage in this research is explained as follows.

a) Problems:

- The average percentage of container problems entering the Exception Area from 23 February 2020 to 7 March 2020 is $7.7 \%$ (quite high).

- Containers that enter the Exception Area with the most problems.

b) Purpose:

Provide information to the company regarding the sigma level of the container problems that enter the Exception Area on February 23, 2020 to March 7, 2020 and the root causes of the containers that enter the Exception Area with the most causes of problems, so that they can be used as a suggestion for improvement.

c) Limitation of the problem:

- Container problems when making transactions at the export gate in the Exception Area on 23 February 2020 to 07 March 2020 are classified based on 5 criteria, namely $\mathrm{BL}=$ Block, $\mathrm{BO}=$ Booking, $\mathrm{CT}=$ Closing Time, $\mathrm{DM}=$ Damage, and ST $=$ System .

- Problems with containers that enter the Exception Area with the most causes. 


\section{2) Measure}

The measure step is carried out to determine key quality characteristics, determine the data collection plan, and measure the performance of the container handling process that enters the Exception Area. The measure stage in this study is described as follows.

a) Quality variables:

The quality variable that measured is the problem of the container when making transactions at the export gate that enters the Exception Area before heading to the container yard based on 5 problem criteria.

\section{b) Measurement of quality variables:}

Measuring the quality variable is by looking at the problem of the container entering the Exception Area according to the 5 problem criteria. Data on the number of container problems that entered the Exception Area on February 23, 2020 to March 7, 2020.

\section{3) Analyze}

At the analysis step, an evaluation of the results of the research is carried out as follows.

a) Poisson Distribution Test

The Poisson Distribution Test is carried out to determine whether the arrival of the container that enters the Exception Area occurs at a certain time. Poisson distribution test results are presented in Table 4 as follows. Hypothesis:

$\mathrm{H}_{0}$ : The number of container problems that enter the Exception Area in accordance with the 5 criteria for problems follow a Poisson distribution

$\mathrm{H}_{1}$ : The number of container problems that enter the Exception Area in accordance with the 5 criteria for problems not follow a Poisson distribution

Significant Level: $\alpha(0,05)$

Rejection Area:Reject $\mathrm{H}_{0}$ if $\chi^{2}>\chi_{\alpha(r-k-1)}^{2}$ or

Statistics Test:

$$
\mathrm{P} \text {-value }<\alpha(0,05)
$$

$$
\text { TABLE } 4 .
$$

POISSON DISTRIBUTION TEST NUMBER OF CONTAINER PROBLEMS ENTERING THE EXCEPTION AREA ACCORDING

\begin{tabular}{ccc}
\multicolumn{3}{c}{ TO 5 PROBLEM CRITERIA } \\
\hline \hline$\chi^{2}$ & $\chi_{(0,05 ; 13)}^{2}$ & $\mathbf{P}_{\text {value }}$ \\
\hline 1,284 & 22,362 & 0,074 \\
\hline
\end{tabular}

Table 4 indicates that the value $\chi^{2}$ amounting to 1,284 worth less than $\chi_{(0,05 ; 13)}^{2}$ amounting to 22,362 and $\mathrm{P}_{\text {value }}$ amounting to 0,074 is worth greater than $\alpha$ amounting to 0,05 , so it was decided that $\mathrm{H}_{0}$ failed to be rejected, which means that the number of container problems that enter the Exception Area is in accordance with the 5 criteria for problems with Poisson distribution.

\section{b) Control Chart U}

Control chart $\mathrm{U}$ for the average number of container problems that enter the Exception Area according to the 5 problem criteria, used to see whether the process is statistically controlled or notis presented in Figure 3 as follows.

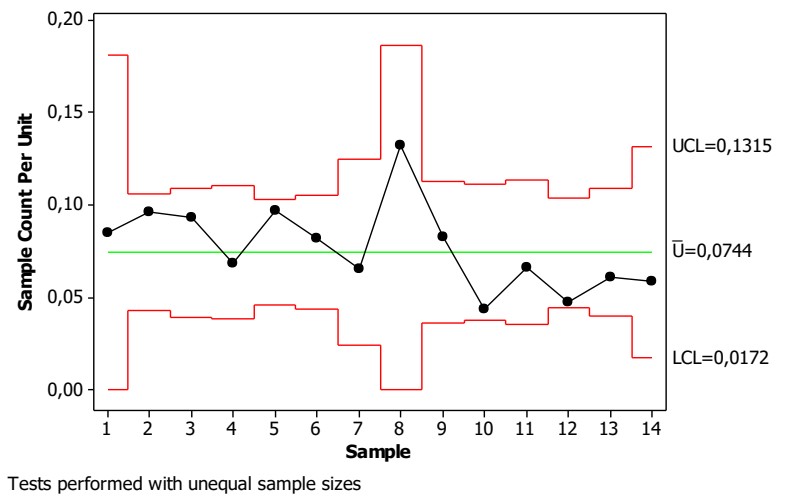

Figure 3. Control Chart U Average Number of Container Problems Entering Exception Area Based on 5 Problem Criteria

Figure 3 shows that the control chart $U$ on the average number of container problems that enter the Exception Area at PT Terminal Petikemas Surabaya has been controlled statistically because no point is outside the control limit.

\section{c) Random Test}

The random test is carried out to determine whether the arrival of the container that enters the Exception Area is not constant or random. The results of the Kecakan Test are presented in Table 5 as follows.

Hypothesis:

$\mathrm{H}_{0}$ : The average number of container problems that enter the Exception Area according to the 5 criteria, the problem occurs randomly

$\mathrm{H}_{1}$ : The average number of container problems that enter the Exception Area according to the 5 criteria, the problem does not occur randomly

Significant Level: $\alpha(0,05)$

Rejection Area : Reject $\mathrm{H}_{0}$ if $r<r_{\operatorname{bottom}}\left(n_{1}, n_{2}\right)$ or

$$
\begin{aligned}
& \text { Statistics Test } \\
& \text { TABLE } 5 . \\
& \text { TEST OF FAMILY THE NUMBER OF CONTAINER PROBLEMS } \\
& \text { ENTERING THE EXCEPTION AREA ACCORDING TO } 5
\end{aligned}
$$

$$
r>r_{\text {top }}\left(n_{1}, n_{2}\right) \text { or } \mathrm{P}_{\text {value }}<\alpha(0,05)
$$

\begin{tabular}{ccccc}
\multicolumn{5}{c}{ PROBLEM CRITERIA } \\
\hline \hline $\mathbf{n}_{1}$ & $\mathbf{n}_{2}$ & $\mathbf{r}_{\text {top }}$ & $\mathbf{r}_{\text {bottom }}$ & $\mathbf{P}_{\text {value }}$ \\
\hline 7 & 7 & 6 & 13 & 0,266 \\
\hline
\end{tabular}

Table 5 shows that the series formed as many as 6 is greater than $r_{\text {bawah }}$ by 3 and smaller than $r_{\text {atas }}$ by 13 and the

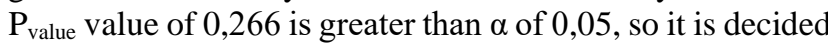
that $\mathrm{H}_{0}$ fails to be rejected, which means the average number of problems containers that enter the Exception Area according to the 5 criteria the problem occurs randomly.

d) Sigma Level

Calculating the sigma level from the average number of container problems that enter the Exception Area according to the 5 problem criteria, the defect value is 487 containers from the number of transactions of 6546 with the chance of the container when the gate in exports enters the Exception Area of 10, so that DPMO is obtained. amounting to 7439,658 . The sigma level is between 2 and 3 , with the calculation in the software: = normsinv $((1000,000-7439,658) / 1000,000)+1,5$, then the sigma level is 3,935 which means the variation or diversity of the container handling process that enters the exception area 
based on OCR's ability to recognize large enough physical containers.

\section{e) Pareto diagram}

Make a Pareto diagram that is used to identify the most common problems with container problems that enter the Exception Area according to the 5 problem criteria. The pareto diagram is presented in Figure 3 as follows.

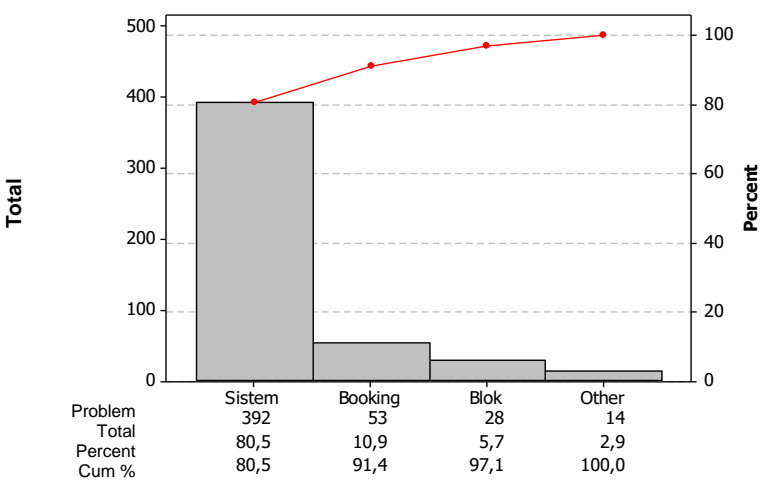

Figure 4. Pareto Diagram of the Number of Container Problems Entering the Exception Area

Figure 4 shows that the biggest problem that causes containers to be constrained when the in gate transaction then enters the Exception Area is the system of $80,5 \%$. After knowing the biggest problem, we continue to look for the root cause of problems in the container which is constrained when the in gate transaction is caused by the system.

f) Ishikawa Diagram

Ishikawa diagram to find out the root cause of container problems in the Exception Area caused by the system is presented in Figure 5 below.

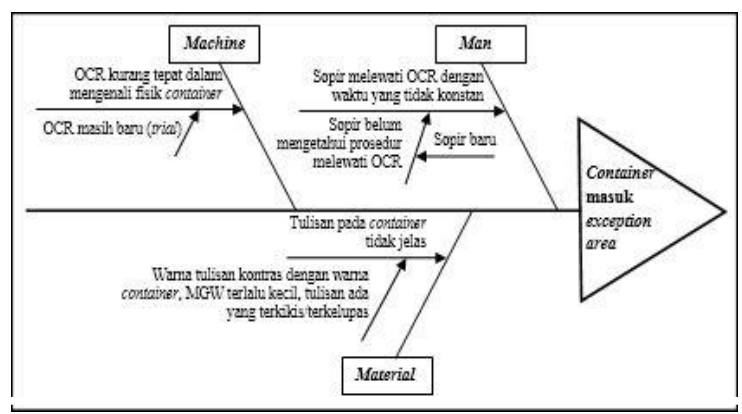

Figure 5. Ishikawa Diagram Number of Container Problems Entering Exception Area Based on OCR Ability to Recognize Physical Containers

Figure 5 shows that the cause of problems in the container which is constrained when the in gate transaction is caused by the system so that it enters the Exception Area when viewed from Man, the problem is that the driver passes the OCR with not constant time because sometimes he still asks tally about the in gate procedure, p. This is because the driver does not understand the procedure when passing OCR and the function of the OCR, but it can also be caused because the driver has just entered PT Terminal Petikemas Surabaya with a gate automation system. When viewed from the Material, the problem is that most of the writing about the container data is not clear, such as the color of the writing contrasts with the color of the container, the MGW writing is too small, the number is peeled off, and the remaining dangerous goods stickers are still stuck / left on the container, so the OCR is sensitive will read it differently according to the physical container. When viewed from the Machine, the problem is that the OCR is not accurate in identifying / recognizing the physical container, it could be due to unclear container information and OCR is still relatively new (trial period). Based on these causes, the resulting effect is that the container enters the Exception Area and the driver goes to the Exception Area to solve the problem assisted by the officer.

4) Improve

a) The improve phase carried out by PT Terminal Petikemas Surabaya on the problems that have been previously identified and analyzed is described as follows.

b) Creating written SOPs that can be seen by the exception area officer and gate superintendent regarding the procedure and target time for resolution of each container problem that enters the exception area so that there is no difference in information and procedures in handling each group of gate officers.

c) Identifying the non-success rate OCR so that the biggest problems caused by the system can be reduced, while minimizing the occurrence of complaints by consignees / importers.

d) Coordinate with the pre in gate security to inform the driver that when passing under the OCR, he must use a constant speed, or alternatively provide audio (such as in Kios $\mathrm{K}$ ) regarding procedures when passing OCR, so that the problem of the container that enters the Exception Area is caused by the system can be minimized.

\section{- Waste identification}

Waste identification is carried out to determine the waste that occurs in the handling process of containers that enter the Exception Area. Types of waste include Environmental Healthy and Safety (EHS), Defect, Waiting, Transportation, Inventory, Motion, and Excess Processing, each of which is described as follows.

1. Environmental Healthy and Safety (EHS)

EHS is a waste related to the health and safety of Exception Area officers, gate supporters, and other officers while in the gate area. At PT Terminal Petikemas Surabaya always prioritizes "safety first" and all people who will enter a restricted area are required to use PPE (Personal Protective Equipment) and pay attention to the health of their workers. However, it is not uncommon for some individuals who do not use PPE while in restricted areas. To prevent this, PT Terminal Petikemas Surabaya should impose punishment for anyone who violates it.

\section{Defect}

Defect in this study is the problem of containers that enter the exception area which is classified based on 5 criteria, namely $\mathrm{BL}=$ Block, $\mathrm{BO}=$ Booking, $\mathrm{CT}=$ Closing Time, DM = Damage, and ST = System.

\section{Waiting}

Waiting time in this study can be seen through the problem of booking (the forwarder has not made a job 
order) having to make a $\mathrm{P} 2$ letter to remove the container then the Exception Area officer rejects the transaction. The problem of container damage is that the forwarder does not carry a CDR (Container Damage Report), so that in both these problems it causes a long handling process which makes the driver wait so that they cannot Rate more containers.

\section{Inventory}

Inventory in this study is the gate operator room that is no longer used, this has led to an increase in the cost of storage, room maintenance, and investment costs of the place. This is actually detrimental to the company, which should not have to spend money if there are no such problems.

\section{Motion}

The motion in this study is excessive movement of the Exception Area officers, including the Exception Area officer having to check into the field if the photo behind the container does not appear. The driver must get off and walk far enough from the parking area to the Exception Area to solve the problem, not to mention if the driver forgets to bring the Driver ID so he has to come back again to get the Driver ID.

\section{CONCLUSION}

The conclusions obtained in this study are as follows.

1. The highest average length of time for containers that enter the Exception Area for each problem is caused by the system and the lowest is due to closing time.

2. The average length of time for container problems that enter the Exception Area based on OCR's ability to recognize incapable physical containers, meaning that the process of solving problems for containers that enter the exception area based on OCR's ability to recognize physical containers has not run according to specifications.

3. The sigma level of the average number of container problems that enter the Exception Area according to the 5 problem criteria, which is 3,935 , which means the variation or diversity of container handling processes that enter the exception area based on OCR's ability to recognize physically large containers.

4. The most problems that cause containers to enter the Exception Area are caused by the system, while the problems for containers that enter the Exception Area with a long completion time of more than one hour are caused by bookings, damage, closing time, and the system.

Advice that can be given to companies:

1. Identify any problems that cause the container to enter the exception area as a further improvement, especially the cause from the internal company because controlling is easier.

2. Calculating the sigma value periodically in order to know the company's performance, especially services at the gate.

3. The company must determine the target number of containers and the resolution time for each container problem that enters the exception area. This is done to make it easier for the company to make improvements.

Suggestions that can be given for further research are further research should not only be carried out on shift 3 , but on shifts 1 and 2 by sampling by sampling so that the results of the analysis are representative because all shifts and handling processes in the Exception Area have the same opportunity.

\section{REFERENCES}

[1] D. C. Montgomery, "Introduction to Statistical Quality Control," 6th ed., United States of America: John Wiley \& Sons, 2009, pp 7980 and pp 314-322.

[2] M. L. George, "Lean Six Sigma for Service," United States of America: McGraw-Hill, 2003, pp 08-10.

[3] L. Wilson, "How to Implement Lean Manufacturing," 2nd ed., United States of America: McGraw-Hill, 2010, pp 26-46.

[4] G. Brue, "Six Sigma for Managers," 2nd ed., United Stated of America: McGraw-Hill, 2002, pp 04-08.

[5] S. H. Kan, "Metrics And Models In Software Quality Engineering," 2nd ed., Boston: Pearson Education, 2003, pp 133-153. 